\title{
Double-scope resection of a large duodenal polyp
}

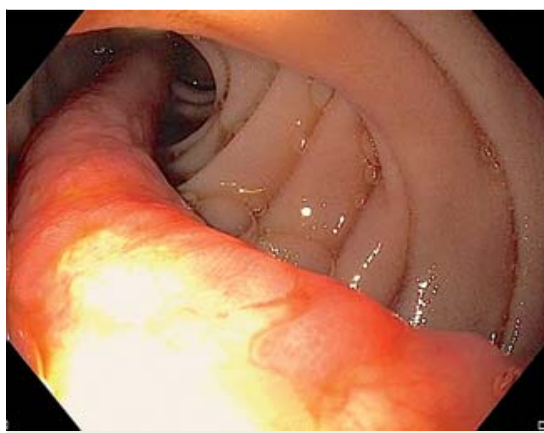

Fig. 1 Duodenal polyp in situ in an 83-yearold man receiving antiplatelet therapy with acetylsalicylic acid and clopidogrel after a myocardial infarction.

An 83-year-old man underwent right colectomy with ileostomy because of Ogilvie syndrome with perforation of the ascending colon. After 10 days, the patient, who had multiple co-morbidities, had a myocardial infarction without ST-segment elevation. For this reason, percutaneous coronary intervention with the application of bare metal stents was required, and he subsequently received the standard dosage of antiplatelet therapy with acetylsalicylic acid and clopidogrel.

Because of recurrent episodes of upper gastrointestinal bleeding with hematemesis and a decreasing hemoglobin level, an esophagogastroduodenoscopy was performed, which identified a large, bleeding, pedunculated polyp at the duodenal bulb ( Fig. 1, Fig.2). Because the stalk of the polyp was more than $10 \mathrm{~cm}$ long, it was impossible to pull the endoscopic snare (FlexSnare; Medwork, Höchstadt/Aisch, Germany) around the stalk. Therefore, an attempt was made to resect the polyp by bending the stalk into a U-shape close to its base in the polypectomy snare (๑ Fig. 3).

Resection with electrocoagulation was intended, but meanwhile bleeding occurred. After the injection of epinephrine $1: 10000$ and the application of hemoclips (Long Clip HX-610-090L; Olympus, Tokyo, Japan), a clear view was restored. The stalk of the polyp had a diameter of approximately $1 \mathrm{~cm}$. The endoscopic snare failed to cut through the whole polyp stalk, which was folded at its base, and caused only tangential injury. An effort was made to dissect the remaining polyp stalk by using the tip of the polypectomy

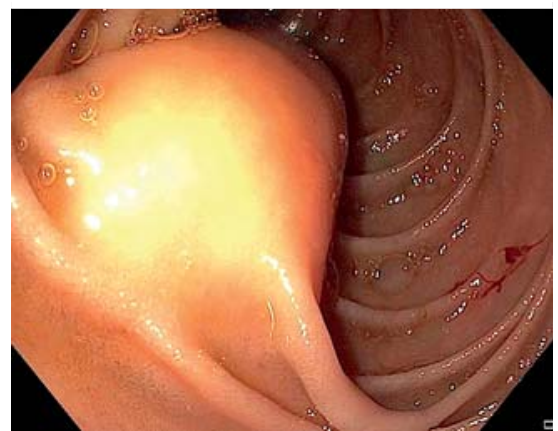

Fig. 2 The base of the polyp.

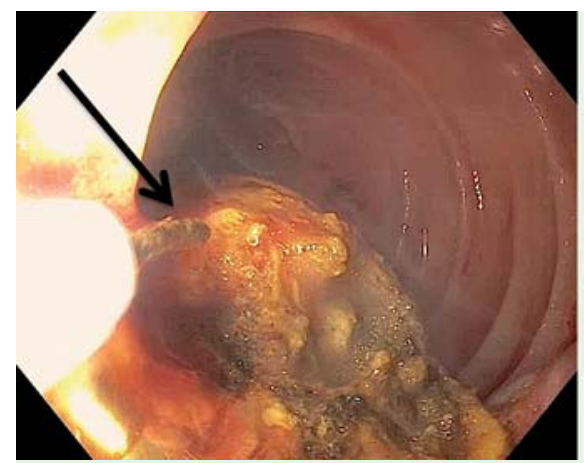

Fig. 4 a Dissection of the polyp base with electrocoagulation and an almost totally closed polypectomy snare (arrow). The resulting tangential cutting plane is clearly visible. b Double-scope resection with the simultaneous use of argon plasma coagulation (star) and the application of tissue tension with an endoscopic grasper (triangle) introduced via the second endoscope.

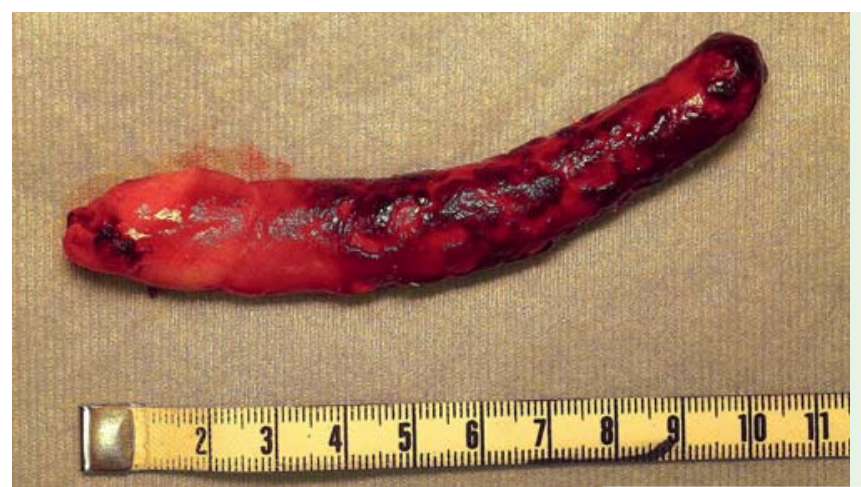

Fig. 5 Resected specimen: a duodenal lipoma with a total length of $11 \mathrm{~cm}$.
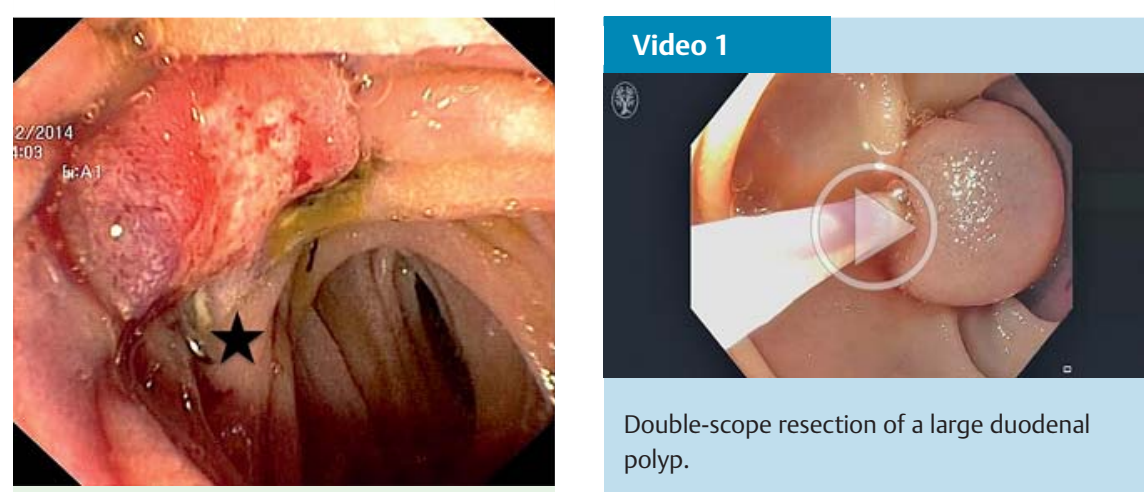

Double-scope resection of a large duodenal polyp.
Fig. 6 Polypectomy site treated with an overthe-scope clip (star). 
snare like a needle knife. However, because of the flat position of the stalk in the duodenum, the orientation of the resection became too tangential to the axis of the polyp ( $\bullet$ Fig.4a).

Next, a pediatric gastroscope (GIFXP190N; Olympus) was introduced into the duodenum in addition to the standard endoscope (GIF-HQ190; Olympus). Now, the polyp stalk could be stretched upward by using a grasper (MTW, Wesel, Germany) and the standard endoscope. Introduction of an argon plasma probe (MABS GIT 1.8-mm probe; KLS Martin, Tuttlingen, Germany) through the pediatric endoscope allowed an uneventful en bloc resection of the polyp close to its base ( Fig.4b). Finally, five hemoclips and $2 \mathrm{~mL}$ of fibrin glue (Tissucol Duo; Baxter Deutschland, Unterschleißheim, Germany) were applied to the polypectomy site to prevent bleeding. The histological appearance of the polyp was that of a submucosal lipoma ( Fig.5). The entire procedure is summarized in - Video 1.

After 1 week, the patient again had a significant decline in his hemoglobin level while on combination therapy with the two antiplatelet agents. Gastroscopy showed rebleeding at the site of the previous polypectomy. Deployment of an over-the-scope clip (OTSC 11/6t; Ovesco
Endoscopy, Tübingen, Germany) successfully stopped the bleeding ( $\bullet$ Fig. 6).

Duodenal lipoma is an uncommon benign tumor with fewer than 230 reported cases $[1,2]$. Depending primarily on their size, gastrointestinal lipomas can become symptomatic and cause, for instance, bleeding, abdominal pain, intestinal obstruction, or intussusception $[3,4]$. In this case, endoscopic polypectomy had to be performed because of bleeding related to the patient's therapy with acetylsalicylic acid and clopidogrel.

The resection of large lipomas may be technically challenging [5]. If resection appears to be impossible with a single gastroscope, the double-scope resection we have described, although maneuverability is difficult, provides an elegant alternative to surgery.

Endoscopy_UCTN_Code_TTT_1AO_2AB

Competing interests: None

\section{Richard F. Knoop, Hans-Jürgen Richter-Schrag, Christine Walker, Robert Thimme, Andreas Fischer}

Interdisciplinary Gastrointestinal Endoscopy, Department of Medicine II, University Hospital Freiburg, Freiburg, Germany

\section{References}

1 Abu Daff SN, Abu Daff NS. Laparoscopic enucleation of a duodenal lipoma, with review of the literature. Saudi Med J 2008; 29: $455-457$

2 Yaman I, Derici H, Paksoy S. Symptomatic duodenal lipoma with endoscopic snare polypectomy. Ulus Cerrahi Derg 2014; 30: $103-105$

3 Lee KJ, Kim GH, Park do Y et al. Endoscopic resection of gastrointestinal lipomas: a single-center experience. Surg Endosc 2014; 28: 185-192

4 Aslan F, Akpinar Z, Cekic C et al. En bloc resection of a $9 \mathrm{~cm}$ giant gastro-duodenal lipoma by endoscopic submucosal dissection. Dig Liver Dis 2015; 47: 88-89

5 Aydin HN, Bertin P, Singh $K$ et al. Safe techniques for endoscopic resection of gastrointestinal lipomas. Surg Laparosc Endosc Percutan Tech 2011; 21: 218222

Bibliography
DOI http://dx.doi.org/
10.1055/s-0034-1393587
Endoscopy 2015; 47: E627-E628
@ Georg Thieme Verlag KG
Stuttgart· New York
ISSN 0013-726X

Corresponding author
Andreas Fischer, MD
University Hospital Freiburg
Interdisciplinary Gastrointestinal Endoscopy
Department of Medicine II
Hugstetter Strasse 55
D-79106 Freiburg
Germany
Fax: +49-761-27025411
andreas.fischer@uniklinik-freiburg.de

